\begin{tabular}{|c|c|c|}
\hline & Int.J.Curr.Microbiol.App.Sci (2016) 5(3): 566-578 & \multirow{4}{*}{ 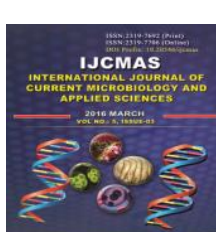 } \\
\hline & \multirow{4}{*}{$\begin{array}{l}\text { International Journal of Current Microbiology and Applied Sciences } \\
\text { ISSN: 2319-7706 Volume } 5 \text { Number 3(2016) pp. 566-578 } \\
\text { Journal homepage: } \underline{\text { http://www.ijcmas.com }}\end{array}$} & \\
\hline & & \\
\hline EXCELLENT & & \\
\hline PUBLISHERS & & \\
\hline
\end{tabular}

Original Research Article

http://dx.doi.org/10.20546/ijcmas.2016.503.066

\title{
An interventional study to decrease healthcare associated burn wound infections in the burn unit of Al Ahrar Hospital in Zagazig city, Sharkia Governorate
}

\author{
Hala Ahmed Magdy Mohamed El-Maghawry ${ }^{1 *}$, WafaaAtwa El Nem², \\ NahedAbd-Allah Sherif ${ }^{2}$ and Sohair Ahmed Hagag ${ }^{2}$ \\ ${ }^{1}$ Assistant Lecturer of Public Health and Community Medicine, Egypt \\ ${ }^{2}$ Professor of Public Health and Community Medicine, Egypt \\ *Corresponding author
}

\begin{abstract}
A B S T R A C T
Keywords

Burn Injury,

Hospital

acquired

infection,

Infection

Control

Measures

Article Info

Accepted:

18 February 2016

Available Online:

10, March 2016

Burn wound infections are one of the most important and potentially serious complications that occur in the acute period following injury. To what extent implementation of guidelines will improve the outcome of burn wound infection in the burn unit? Implementation of guidelines will $r$ educe the incidence rate of burn wound infection in the burn unit.Reducing morbidity and of health care associated burn wound infection in the burn unit of Al- Ahrar hospital. An interventional study was used where all patients with burn injuries who were admitted to the burn unit of Al- Ahrar hospital during the period of the study (6 months before the intervention from the $1^{\text {st }}$ of July 2014 to the end of December 2014 and 6 months after the intervention from the $1^{\text {st }}$ of February 2015 till the end of July 2015) patients were assessed regularly during their hospital admission for occurrence of burn wound infections, the time of its occurrence and the agent causing it. All workers staff who shared in patient care in the burn unit were also included in this study to assess the infection control procedures adopted in the unit. And assessment of the level of knowledge of the working staff of the burn unit of $\mathrm{Al}$ Ahrar Hospital (including physicians, nurses and workers) before and after the intervention was done. There were statistically differences between physician's knowledge, nurse's knowledge and workers' knowledge about hospital acquired infection and infection control procedures before and after the health education intervention. As regarding the performance of the health care providers, there was a significant difference regarding hand washing procedure and hand scrubbing, application of the aseptic technique of wound inspection and dressing, using gloves, aprons and gowns in the burn unit before and after the health education program.Implementation of simple education program to the working staff of the burn unit increased adequacy of knowledge, improved the practice of healthcare providers as regarding the infection control standard precautions and reduced burn wound infection rates in the burn unit during the intervention period.Emphasizing the importance of latest evidence-based practices of infection control in continuing education / training programs, strict observation of their performance/ utilization of infection control standard precautions, equipment and surfaces should be appropriately decontaminated before storage.
\end{abstract}

\section{Introduction}

A burn is defined as an injury to the skin or other organic tissue primarily caused by thermal or other acute trauma. It occurs when some or all of the cells in the skin or 
other tissues are destroyed by hot liquids (scalds), hot solids (contact burns from hot surfaces such as stoves, heaters), or flames (flame burns). Injuries to the skin or other organic tissues due to radiation, radioactivity, electricity, friction or contact with chemicals are also identified as burns. A burn, irrespective of etiology, is clearly an acute wound, as opposed to a chronic wound. ${ }^{1}$

HAI (previously called nosocomial infection) refers to infections associated with health care delivery in any setting (e.g., hospitals, long-term care facilities, community/ambulatory settings, and home/community care). An HAI is defined as a localized or systemic infection that results from an adverse reaction to the presence of an infectious agent(s) or its toxin(s), for which there is no evidence of infection on admission to a health care facility. $^{2}$

Infections in burn patients represent a serious complication of thermal injury and include: Burn wound infection, pneumonia, intravascular catheter associated infections and suppurative thrombophlebitis, urinary tract infection, sepsis and toxic shock syndrome. ${ }^{4}$

Infection in the burn patient is a leading cause of morbidity and mortality and remains one of the most challenging concerns for the burn team as it reduces the effectiveness of treatment and increases morbidity, mortality, and cost of care. The prevention and control of infectious diseases among burned patients present a specialized problem, as the environment in burn units can become contaminated with resistant organisms. Lack of proper wound care, edema formation and lack of resuscitation may actually increase the size and/or depth of the wound. Therefore, developing an educational and training program for infection control of burned patients, leads to reducing morbidity and mortality from burn. Also reduce disabilities that occur as a result of burn. Moreover there will be marked reduce in hospital admission days. ${ }^{5}$

\section{Research Question}

To what extent implementation of guidelines will improve the outcome of burn wound infection in the burn unit?

\section{Hypothesis}

Implementation of guidelines will reduce the incidence rate of burn wound infection in the burn unit.

The main aim of this study includes, reducing morbidity and mortality of health care associated burn wound infection in the burn unit of Al- Ahrar hospital.

\section{Subjects and Methods}

An interventional study was conducted in the bum unit of Al- Ahrar hospital in Zagazig city, Sharkia governorate where studied patients were assessed regularly during their hospital admission for occurrence of burn wound infections, the time of its occurrence and the agent causing it. The infection control procedures adopted in the unit were also assessed regularly and compared to the standard precautions. And assessment of the level of knowledge of the working staff of the burn unit of Al Ahrar Hospital (including physicians, nurses and workers) before and after the intervention was done.

\section{Tools used in the Study}

Data for the present study was collected by the following tools: 


\section{For Patients}

Questionnaire included the following items:

Socioeconomic characteristics including name, age, sex, marital status, education, working status. The medical history of cases. The history of the burn injury.

Admission sheet: Patients' records were reviewed to obtain information pertinent to: Date of admission and date of discharge, degree of burn and total body surface area burnt TBSA\% and treatment regimen applied.

Follow up sheet of patients: It included clinical assessment of the wound and results of swab cultures.

Management and outcome of infected burn wound: This sheet was conducted to collect data including management done to the infected wound and the outcome of infected wound.

\section{For the Healthcare Personnel and the Cleaning Staff}

Structured questionnaire (pre and post-test) to assess knowledge about infection control.

Checklists to assess the performance: Based on the standard procedures required by the WHOas well as the Egyptian National Guidelines on infection control, the checklists were developed to record the observation of the procedures adopted inside the burn unit compared to the standard.

\section{Procedure}

\section{Phase I (Pre-intervention)}

Once permission was granted to proceed with the proposed study,field visits to the unit were conducted three times weekly during the period of the field study where newly admitted patients interviewed and already included patients followed up to complete the follow up sheet which was designed to diagnose burn wound infections. For the healthcare personnel, the infection control procedures adopted in the unit were observed regularly during the visits and completion of the checklists were done weekly. For the cleaning staff observations were done on the middle and the end of each month for checklists assessing the housekeeping process and the special precautions for the burn unit and on the end each month for checklists assessing waste management.

\section{The Intervention Phase}

A structured educational program was designed after reviewing related literature (guidelines recommended by WHO as well as the Egyptian National Guidelines) in the form of an instructional booklet for the purpose of gaining knowledge and information and was disseminated in the burn unit as arabic posters were distributed as handout to all health care providers in burn unit. Lectures (power point including videos for demonstration of the practical steps).

\section{Phase II (Post Intervention)}

For the patients: Field visits to the unit were conducted three times weekly during the period of the field study where newly admitted patients interviewed and already included patients followed up to complete the follow up sheet which was used in Phase I to diagnose burn wound infections. For the healthcare personnel, the infection control procedures adopted in the unit were observed regularly during the visits and completion of the checklists were done weekly. For the cleaning staff on the middle 
and the end of each month for checklists assessing the housekeeping process and the special precautions for the burn unit and on the end each month for checklists assessing waste management.

\section{Statistical Analysis}

Collected data were tabulated. For quantitative variables mean, standard deviation, and range (minimum and maximum) were calculated. For qualitative variables number and percentage were calculated. $t$ test was used in quantitative data of normal distribution. For qualitative variables Chi square test, Fisher's exact test and Mcnemar test were used. All tests was used at a level of significance $\leq 5 \%$

\section{Ethical Considerations}

Ethical considerations were taken through the whole study including fully informed participants with the purpose and nature of the study and then oral consent was taken from participants. Coded numbers for each participant was used to guarantee privacy. An official approval for the implementation of the study was obtained from the burn unit of $\mathrm{Al}$ Ahrar hospital and approval from the Institutional review board (IRB) was taken.

\section{Results and Discussion}

Table (1) shows socio-demographic characteristics of studied patients in the burn unit of Al Ahrar hospital in both phases of the study. It portrays that there is no difference between both groups in phase I and II as regards sex, marital status and social class while there is a significant difference between both groups as regards the age $(p=0.04)$.

Table (2): showing the incidence of burn wound infections among studied patients, this table shows that the incidence of burn wound infection in phase I is $(72.3 \%)$ while the incidence of burn wound infection in phase II is $(68.9 \%)$ with no significant difference between both groups.

Table (3) portrays the relation between patients' age and the occurrence of burn wound infections. As regard sex, the differences are statistically insignificant among patients in both phases. Infected females in phase I constituted (74.7\%) compared to $(73.9 \%)$ among infected patients in phase II.

Table (4) shows that there is a significant difference between physician's knowledge about hospital acquired infection and infection control procedures before and after the health education intervention.

Table (5) shows that there is a significant difference between nurse's knowledge about burn, hospital acquired infection and infection control procedures before and after the health education program.

Table (5) shows that there is a significant difference regarding hand washing procedure and hand scrubbing in the burn unit before and after the health education program.

Table (6) shows that there is no significant difference before and after the health education program as regards the infection control precautions specified for the burn unit.

Health care associated infections are caused by pathogens that easily spread through the body. Many hospital patients have compromised immune systems, so they are less able to fight off infections. In some cases, patients develop infections due to poor conditions at a hospital or a healthcare facility, or due to hospital staff not following proper procedures. Some patients acquire nosocomial infections by interacting with other patients. Others encounter bacteria, 
fungi, parasites, or viruses in their hospital environment $^{6}$

Burn wound infections are one of the most important and potentially serious complications that occur in the acute period following injury. The most important patient characteristics that influence morbidity and mortality from burn wound infection and sepsis include large TBSA wounds (>30\%), significant amounts of full-thickness burns, prolonged open wounds or delayed initial burn wound care. Factors that have favorably impacted the incidence of burn wound infection include early wound closure, topical and prophylactic antimicrobial therapy and advances in infection control measures in modern burn units.

The present study comprised a total number of 141 burn patients who were admitted in the burn unit ofAl- Ahrar hospital in phase I and 132 patients in phase II during the period of the study; nearly three quarters of them $(64.5 \%$ in phase I and $76.5 \%$ in phase II) were from 10 to 50 years old. This is in accordance with a study in Egypt in which $(66.1 \%)$ of the burn victims were between the ages of 11-50 years old with peak incidence at $31-40$ years (21.7\%).While this finding is different from a study that stated children younger than 5 Years account for almost half of the population with burn injury ${ }^{7,8}$. (Table 1)

As regards their sex, $56 \%$ in phase I and $52.3 \%$ in phase II were females. This may be explained by the fact that females, being housewives, were mostly burned at home due to poor architectural design of the cooking places and placing flammable articles and stoves outside kitchen or at open spaces due to the fact that some families seemed to be living in a single room where they do all activities including cooking and sleeping due to lack of enough space to live in. This is in accordance with a studythat stated that females were more frequently victims of burns than males. And this finding is different from a study in Switzerland in which there was overall male predominance of $55 \%$ to $75 \%$. This was explained by the fact that burn injuries in adults are often work related. Most of patients were married $(65.1 \%$ in phase I and $43.9 \%$ in phase II) and more than half of them $51.1 \%$ in phase I and $51.5 \%$ in phase II) were of low social class according to the score applied. These findings were similar to the sample ofother studywhere $(53.1 \%)$ of the sample were females and stated a vital piece of information lies in the fact that females, being housewives, were mostly burned at home. In a study in India, female not only outnumbered the males, but the sex ratio being almost three times higher in female $^{8-11}$. (Table 1)

As regards the description of the burn accident, Table (2) showed that about half of the patients had burn accident due to flame burn in phase I (48.2\%). This may be explained by the fact of being near to flammable articles and stoves mainly in kitchen for cooking which is responsible for most of the household flame among the female population. This is similar to finding of a study in whichtheyfound that females were mostly victims of flame burns, since they were housewives mainly concerned with cooking.In phase II, fifty three percent of patients in phase were due to scald injury. This finding was also in accordance with a study in which they stated that all age groups, scalding from hot liquids accounted for one-third to one-half of all burns (Table 2).

Also findings from four studies in Finland, Spain, Turkey, and Slovakia stated that Flames, scalds (including steam), and 
contact burns were the top three causes of severe burns(Table 2).On asking about first aid measures done before admission, (73\% and $68.2 \%$ ) of patients mentioned its application in both phase I and II respectively near to the site of the accident before their referral to the burn unit.in a study in Tanzania it was revealed that immediately after the burn injury several topical agents were applied as a first aid measures ${ }^{8,10,12,13}$ (Table 2).

Table (3) illustrated the description of the burn wound of the studied patients, and their outcome. As regards the degree of burn depth, in practice the burn wound usually contains areas of differing depth, so patients were classified according to the predominant burn depth where $(51.8 \%)$ of patients in phase I had burn wounds of the $3^{\text {rd }}$ degree while $(52.3 \%)$ of patients in phase II had burn wounds of the $2^{\text {nd }}$ degree. As regards TBSA\%, more than three quarters of patients in phase I $(83.7 \%)$ had burn wounds with TBSA\% more than $20 \%$. In phase II, three quarters of patients in phase II $(75 \%)$ had burn wounds with TBSA\% more than $20 \%$. This finding different from a study in which there was few cases of burns totaling more than $50 \%$ of the TBSA and also different from other study in which there was only $(23.7 \%)$ sustained burns of 20 $40 \%$ TBSA $^{12,14}$ (Table 3).

From the present study it was found that, the mean duration of hospitalization of studied patients was 17.9 days and ranged from 6 to 34 days in phase I and the mean duration of hospitalization of studied patients in phase II 15.6 days and ranged from 8 to 29 days. These findings were similar to that reported by other study in whichthe mean length of hospitalization in the general population with burn injuries was 7 to 33 days and was reduced by $26 \%$. Also these findings were similar to finding of an interventional study in which the mean hospital stay of the patients with nosocomial infection was reduced from 45.4 days to 34.0 days ${ }^{8,15}$ (Table 4).

On studying the incidence of burn wound infections, the clinical assessment of the burn wound done by the resident physician as well as the results of swab cultures from it were taken into consideration. In this study the incidence of burn wound infection decreased from $72.3 \%$ to $68.9 \%$ after intervention. This was in accordance with a study in which nosocomial infection rates were reduced by $23.8 \%{ }^{15}$ (Table 2).

Various possible risk factors were investigated for their role in burn wound colonization in burn units. In looking at patient age, it was noted that $(79.5 \%)$ of patients over 50 years old had infected wounds compared with $(20.5 \%)$ of patients in the same age group in phase I and this difference is statistically significant $(\mathrm{P}=0.02)$. In different from a study in which there were positive cultures among (49.4\%) at < 15 years old group (pediatric) in contrast to $(39.4 \%)$ at $\geq 15$ years old group (adult), although the difference was statistically unsignificance $(\mathrm{P}$ value $=$ 0.328). and This was explained by the mobility of children compared to adults and the children's general curiosity and hyperactivity in moving around the burn unit environment would also make them more prone to colonization (Table 3). As regard sex, Table (3) reveals that among infected patients, females constituted (73.9\%) compared to $(26.1 \%)$ among non infected patients in phase II. This differences are statistically insignificant $(\mathrm{P}=0.11)$. This could be due to the higher number of female patients $(56 \%$ in phase I and $52.3 \%$ in phase II) compared to male patients. 
Table.1 Socio-Demographic Characteristics of Studied Patients in the Burn Unit of Al Ahrar Hospital in Both Phases of the Study

\begin{tabular}{|c|c|c|c|c|c|}
\hline \multirow{2}{*}{$\begin{array}{c}\text { Socio-demographic } \\
\text { character }\end{array}$} & \multicolumn{2}{|c|}{$\begin{array}{l}\text { Phase I } \\
(n=141)\end{array}$} & \multicolumn{2}{|c|}{$\begin{array}{l}\text { Phase II } \\
(n=132)\end{array}$} & \multirow[t]{2}{*}{$\begin{array}{c}X^{2} \text { test } \\
\text { (P value) }\end{array}$} \\
\hline & No & $\%$ & No. & $\%$ & \\
\hline \multicolumn{6}{|l|}{ Age (years) } \\
\hline 1 - & 11 & 7.8 & 11 & 8.3 & \multirow{3}{*}{$\begin{array}{c}6.34 \\
(0.041)\end{array}$} \\
\hline 10 - & 91 & 64.5 & 101 & 76.5 & \\
\hline $50+$ & 39 & 27.7 & 20 & 15.2 & \\
\hline \multicolumn{6}{|l|}{$\overline{\overline{\text { Sex }}}$} \\
\hline Male & $\overline{62}$ & 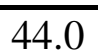 & 63 & $\overline{447.7}$ & \multirow{2}{*}{$\begin{array}{c}0.387 \\
(0.534) \\
\end{array}$} \\
\hline Female & 79 & 56.0 & 69 & 52.3 & \\
\hline \multicolumn{6}{|l|}{ Marital status } \\
\hline Married & 79 & $\overline{56.1}$ & 58 & 43.9 & \multirow{3}{*}{$\begin{array}{c}5.32 \\
(0.06)\end{array}$} \\
\hline Below age of marriage* & 24 & 17.1 & 36 & 27.3 & \\
\hline Other** & 38 & 26.8 & 38 & 28.8 & \\
\hline \multicolumn{6}{|l|}{ Social class } \\
\hline$\overline{\text { Low }}$ & 72 & 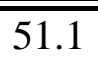 & 68 & $\overline{51.5}$ & \multirow{3}{*}{$\begin{array}{c}0.617 \\
(0.735)\end{array}$} \\
\hline Moderate & 65 & 46.1 & 58 & 43.9 & \\
\hline High & 4 & 2.8 & 6 & 4.6 & \\
\hline
\end{tabular}

* Under 18 years old; **Other: Single, widow or divorced

Table.2 Description of the History of the Burn Accident among the Studied Patients in the Burn Unit of Al Ahrar Hospital

\begin{tabular}{|c|c|c|c|c|c|}
\hline \multirow{2}{*}{$\begin{array}{l}\text { Description of the burn } \\
\text { accident }\end{array}$} & \multicolumn{2}{|c|}{ Phase I $(n=141)$} & \multicolumn{2}{|c|}{ Phase II $(n=132)$} & \multirow{2}{*}{$\begin{array}{c}\mathrm{X}^{2} \text { test } \\
(\mathrm{P} \text { value })\end{array}$} \\
\hline & No. & $\%$ & No. & $\%$ & \\
\hline \multicolumn{5}{|l|}{ Cause of burn } & \multirow{5}{*}{$\begin{array}{c}4.615 \\
(0.202)\end{array}$} \\
\hline Flame & 68 & 48.2 & 59 & 44.7 & \\
\hline Scald & 64 & 45.4 & 70 & 53.0 & \\
\hline Electrical & 3 & 2.1 & 0 & 0.0 & \\
\hline Chemical & 6 & 4.3 & 3 & 2.3 & \\
\hline \multicolumn{6}{|l|}{ First aid } \\
\hline Done & 103 & 73.0 & 90 & 68.2 & \multirow{2}{*}{$\begin{array}{c}0.780 \\
(0.377)\end{array}$} \\
\hline Not done & 38 & 27.0 & 42 & 31.8 & \\
\hline \multicolumn{6}{|l|}{ Transportation method } \\
\hline Ambulance & 78 & 55.3 & 81 & 61.4 & \multirow{2}{*}{$\begin{array}{c}1.024 \\
(0.312) \\
\end{array}$} \\
\hline Private car or taxi & 63 & 44.7 & 51 & 38.6 & \\
\hline
\end{tabular}


Table.3 Degree and Size of Burn wound among the Studied Burn Patients in the Burn unit of Al Ahrar Hospital

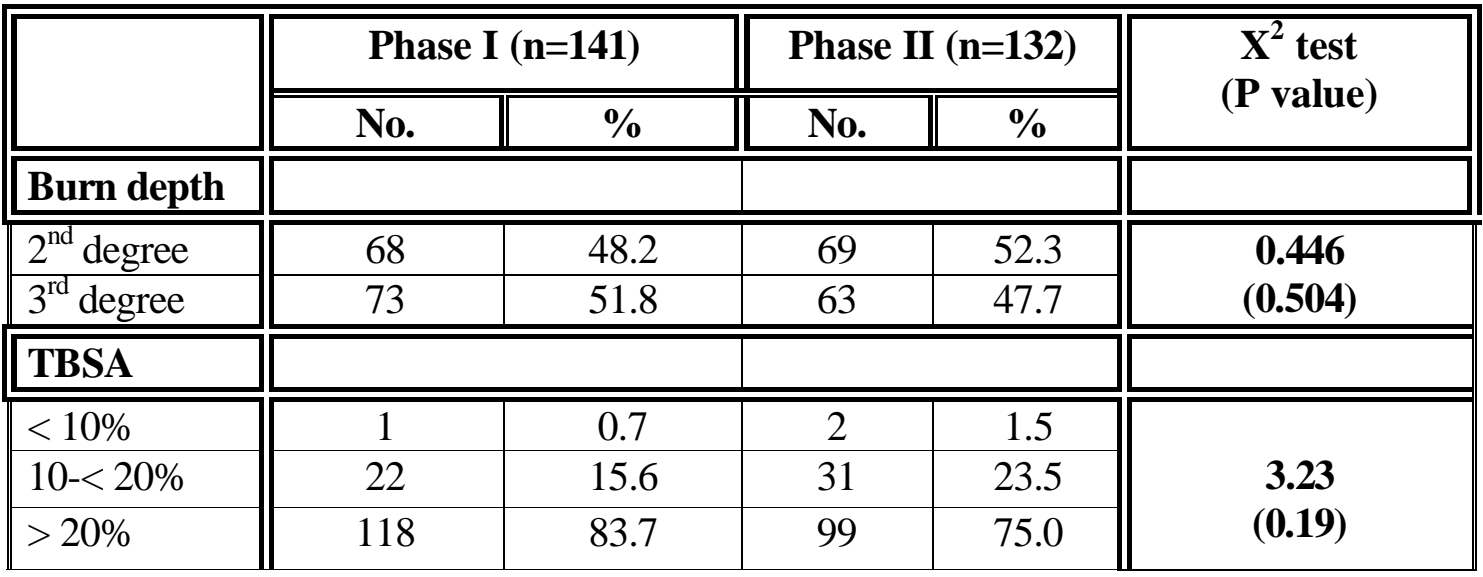

Table.4 Duration of Hospitalization among the Studied Patients in the Burn unit of Al Ahrar Hospital

\begin{tabular}{|l||c||c|c|}
\hline Duration of hospitalization (in days) & Phase I & Phase II & $\begin{array}{c}\text { t test } \\
\text { (P value) }\end{array}$ \\
\hline \hline Mean \pm SD & $17.9 \pm 7.3$ & $15.6 \pm 65.4$ & $\begin{array}{c}\mathbf{1 7 . 5} \\
\text { Range }\end{array}$ \\
\hline
\end{tabular}

Types and Simplified Criteria for Surveillance of Nosocomial Infections (WHO, 2002)

\begin{tabular}{|c|c|}
\hline $\begin{array}{l}\text { Type of nosocomial } \\
\text { infection }\end{array}$ & Simplified criteria \\
\hline Surgical site infection & $\begin{array}{l}\text { Any purulent discharge, abscess, or } \\
\text { spreading cellulitis at the surgical } \\
\text { site during the month after the } \\
\text { operation }\end{array}$ \\
\hline Urinary infection & $\begin{array}{l}\text { Positive urine culture } \\
\text { ( } 1 \text { or } 2 \text { species) with at least } \\
10^{5} \text { bacteria/ml, with or without } \\
\text { clinical symptoms }\end{array}$ \\
\hline \multirow[t]{4}{*}{ Respiratory infection } & $\begin{array}{l}\text { Respiratory symptoms with at } \\
\text { least two of the following signs } \\
\text { appearing during hospitalization: }\end{array}$ \\
\hline & - cough \\
\hline & — purulent sputum \\
\hline & $\begin{array}{l}\text { new infiltrate on chest } \\
\text { radiograph consistent with } \\
\text { infection }\end{array}$ \\
\hline $\begin{array}{l}\text { Vascular catheter } \\
\text { infection }\end{array}$ & $\begin{array}{l}\text { Inflammation, lymphangitis or } \\
\text { purulent discharge at the insertion } \\
\text { site of the catheter }\end{array}$ \\
\hline Septicaemia & $\begin{array}{l}\text { Fever or rigours and at least one } \\
\text { positive blood culture }\end{array}$ \\
\hline
\end{tabular}


Table.5 The Incidence of Burn wound Infections among Studied Patients in the Burn unit of Al Ahrar Hospital

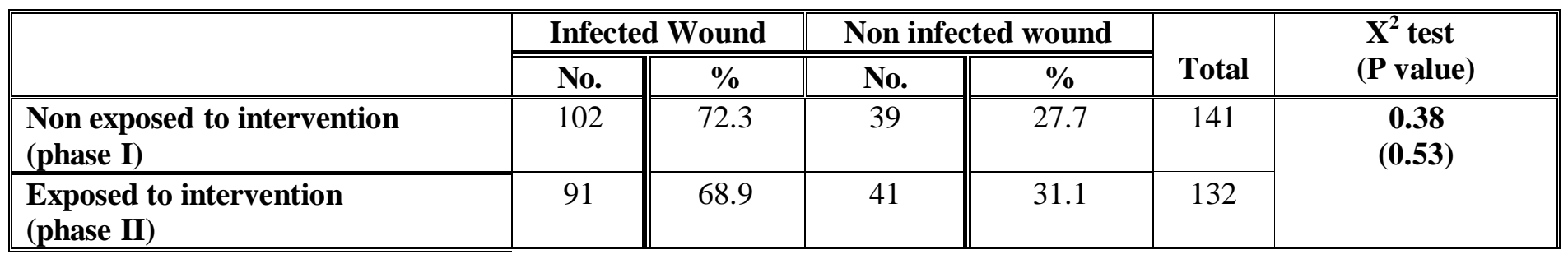

Table.6 The Relation Between Some Demographic Characteristics and the Occurrence of Burn Wound Infections among Studied Patients in the Burn Unit of Al Ahrar Hospital

\begin{tabular}{|c|c|c|c|c|c|c|c|c|c|c|}
\hline \multirow{3}{*}{$\begin{array}{l}\text { Demographic } \\
\text { factors }\end{array}$} & \multicolumn{4}{|c|}{ Phase I } & \multirow{3}{*}{ Total } & \multicolumn{4}{|c|}{ Phase II } & \multirow{3}{*}{ Total } \\
\hline & \multicolumn{2}{|c|}{ Infected wounds } & \multicolumn{2}{|c|}{$\begin{array}{l}\text { Non infected } \\
\text { wounds }\end{array}$} & & \multicolumn{2}{|c|}{ Infected wounds } & \multicolumn{2}{|c|}{$\begin{array}{l}\text { Non infected } \\
\text { wounds }\end{array}$} & \\
\hline & $\begin{array}{c}\text { No } \\
(n=102)\end{array}$ & $\%$ & $\begin{array}{c}\text { No } \\
(n=39)\end{array}$ & $\%$ & & $\begin{array}{c}\text { No } \\
(\mathrm{n}=91)\end{array}$ & $\%$ & $\begin{array}{c}\text { No } \\
(n=41)\end{array}$ & $\%$ & \\
\hline \multicolumn{11}{|l|}{ Age: } \\
\hline $1-$ & 11 & 100 & 0 & 0.0 & 11 & 10 & 90.9 & 1 & 9.1 & 11 \\
\hline $10-$ & 60 & 65.9 & 31 & 34.1 & 91 & 70 & 69.3 & 31 & 30.7 & 101 \\
\hline $50+$ & 31 & 79.5 & 8 & 20.5 & 39 & 11 & 55.0 & 9 & 45.0 & 20 \\
\hline $\begin{array}{c}\mathrm{X}^{2} \text { test } \\
(\mathrm{P} \text { value }) \\
\end{array}$ & \multicolumn{5}{|c|}{$\begin{array}{r}7.06 \\
(0.02) \\
\end{array}$} & \multicolumn{5}{|c|}{$\begin{array}{c}4.3 \\
(0.11) \\
\end{array}$} \\
\hline \multicolumn{11}{|l|}{ *Sex: } \\
\hline -Male & 43 & 69.4 & 19 & 30.6 & 62 & 40 & 63.5 & 23 & 36.5 & 63 \\
\hline -female & 59 & 74.7 & 20 & 25.3 & 79 & 51 & 73.9 & 18 & 26.1 & 69 \\
\hline $\begin{array}{c}\mathrm{X}^{2} \text { test } \\
(\mathrm{P} \text { value }) \\
\end{array}$ & \multicolumn{5}{|c|}{\begin{tabular}{|l|}
$\mathbf{0 . 4 9 3}$ \\
$(\mathbf{0 . 5 7})$ \\
\end{tabular}} & \multicolumn{5}{|c|}{$\begin{array}{c}1.67 \\
(0.196) \\
\end{array}$} \\
\hline \multicolumn{11}{|l|}{ *Social class } \\
\hline -Low & 60 & 83.3 & 12 & 16.7 & 72 & 46 & 65.7 & 24 & 34.3 & 70 \\
\hline -Moderate & 41 & 63.1 & 24 & 36.9 & 65 & 40 & 71.4 & 16 & 28.6 & 56 \\
\hline -High & 1 & 25.0 & 3 & 75.0 & 4 & 5 & 83.5 & 1 & 16.7 & 6 \\
\hline $\begin{array}{c}\text { Fisher exact test } \\
\text { (P value) }\end{array}$ & \multicolumn{5}{|c|}{$\begin{array}{c}11.6 \\
(0.003)\end{array}$} & \multicolumn{5}{|c|}{$\begin{array}{cc}1.08 \\
(0.581) \\
\end{array}$} \\
\hline
\end{tabular}

This finding is different from a study in which males had more positive cultures $(50.7 \%)$ than female patients $(40.8 \%)$, but the difference was not statistically significant $(\mathrm{P}$ value $=0.288)$. Concerning the social class of patients, most of infected patients in phase I were of low social class $(83.3 \%)$ compared to $(16.7 \%)$ in non infected patients. However this difference is statistically significant $(\mathrm{P}=0.003)$. This may be explained by the prevalence of low socioeconomic groups where poor hygienic conditions prevail; malnutrition may also play a role in the earlier establishment of the infection (Table 3$)^{16}$.

Regarding the effect of the health education program on physician's knowledge about burn and prevention of hospital acquired infection in the burn unit; Table (4) portrays no significant difference between both groups before and after application of the 
intervention as physician's knowledge about burn definition, causes and degree was good in the pre-intervention stage. While there is significant difference between both groups before and after application of the intervention as regarding knowledge about infection control procedures. Regarding nurse's knowledge about burn, hospital acquired infection and infection control procedures; Table (5) shows significant difference between both groups before and after application of the intervention. This finding is in accordance with a study in which nurses' knowledge regarding burn (definition. causes \& calculation of burn area) and nosocomial infection in burn unit was low. ${ }^{17}$ This is different from a study in which the majority of their studied groups aware with, what infection is, and how it is transmitted. ${ }^{18,19}$

As regard hand washing procedure, Table (6) shows that more than half of observations $(63.2 \%)$ in the pre-intervention phase were unsatisfactory, showed wrong technique. They didn't remove jewelry or watch worn before hand washing. In other observations, physicians rinsed their hands under running tape water only without rubbing of the hands or use of detergents. In all of the observations, hands were dried using a small piece of clean gauze and they turned tap with their hands. These findings are in accordance with a study in Alexandria burn unit in which the resident physicians entered the unit daily without washing their hands and more than three quarters of observations were unsatisfactory regarding hand washing technique ${ }^{20}$. After applying the health education program, the majority of observations $(88.6 \%)$ were satisfactory with a significant difference between both groups before and after the health education program. This finding is in accordance with a study in which the frequency of hand hygiene performance significantly increased during the study period at the intervention ${ }^{21}$. Regarding observations on hand washing facilities, only $(51.1 \%)$ of observations were satisfactory as hand washing facilities were deficient in the unit. There were no sinks in patients' rooms or just outside it. Only one patient's room contains sink inside it and the other three sinks in the unit are located in the nurses' counter, in the operating room and in the shower treatment room. Detergent was supplied to the unit in the form of soap bars (large bars) and disinfectant supplied to the unit was Betadine (povidone iodine). In the pre-intervention phase, there were no paper towels or clean towels to be used in drying hands at any time during the field visits.

These findings are in accordance with a study for in which there were no detergent or disinfectant available on sinks all the time as detergent were stored and brought to use only before wound dressing sessions to be removed again after being used during the session. ${ }^{20}$ In the post-intervention phase, there was (82) satisfactory observations out of (132) observations which were collected during the field study as hand washing detergent and paper towels became available on every sink but with insignificant difference between both groups before and after the health education program as sinks still absent from every patients room. This finding is in accordance with a study in which the frequency of applying hand hygiene facilities significantly increased during the study period at the intervention ${ }^{21}$. For assessment of the process of hand scrubbing before burn wound dressing, (141) observations were collected from the working staff (physicians and nurses) during the pre-intervention phase. In (82) observations out of the (141) observations was unsatisfactory as the physicians didn't scrub or wash their hands at all before wearing the sterile gloves for dressing or 
physicians rinse their hands only under running tape water even without use of any detergent or disinfectant. These findings are similar to a study for in which there were (89) unsatisfactory observations were collected from nurses during the field study because nurses alone were responsible of changing patients' dressings ${ }^{20}$. In the postintervention phase, only $(29.5 \%)$ of observations were unsatisfactory with a significant difference between both groups before and after the health education $\operatorname{program}(\mathrm{P}<0.05)$.

Regarding the infection control procedures specified to the burn unit, Table (7) revealed unsatisfactory observations as at the entry of the unit there was no sink for hand washing before entry to the unit. No one enter the unit either from the health care staff nor do the visitors wash their hands before entry. There was a uniform for staff in the unit but wasn't always used and they didn't change their clothes before entry. The burn unit wasn't air conditioned and windows were opened all the time. Beds inside the unit carried water-proof mattresses which were wiped over with a disinfectant daily and washed and dried after patient discharge. Visitors allowed to enter the unit not wearing any personal protective equipment (clean gowns and overshoes, but, no masks and gloves). In the post-intervention phase, the satisfactory observations increased from $(36.2 \%)$ to $(46.9 \%)$ but with insignificant difference between both groups before and after the intervention $(p>0.05)$ as the uniform for staff in the unit was used and they change their clothes before entry to the unit.

In conclusion, infection is one of the main complications among burned patients. This study revealed that a relatively simple education program for implementation of evidence based guidelines recommended by CDC and improvement of infection control infrastructure reduced burn wound infection in the burn units by a little percentage from $(72.3 \%)$ to only $(68.9 \%)$ as risk factors of occurrence of burn wound infection not only include management factors but also include burn factors and patients factors. Based on the findings of this study, it can be concluded that implementation of simple education program to the working staff of the burn unit increased adequacy of knowledge, improved the practice of healthcare providers as regarding the infection control standard precautions and reduced burn wound infection rates in the burn unit during the intervention period.

\section{Recommendations}

The current study recommends the following:

Emphasizing the importance of latest evidence-based practices of infection control in continuing education / training programs.

Strict observation of their performance/ utilization of infection control standard precautions and correction of poor practices by the infection control team are required in the form of strictly enforcing hand washing and the universal use of personal protective equipment (gowns, gloves, and masks). Health care personnel must be gowned (including use of disposable or reusable gowns and disposable plastic aprons to prevent soiling of health care workers' clothing during wound care procedures) and gloved at each entry to the burn patient's isolation room.

Equipment and surfaces should be appropriately decontaminated before storage or use on other patients.

Providing training programs for newly joined physicians and nurses about infection 
control standard precautions and at regular intervals.

Availability of all facilities and equipments required for applying infection control standard precautions.

Burn wound infections should be rigorously monitored according to the standard definitions in order to generate accurate epidemiological data about infection rates. Routine surveillance should also be carried out for other types of healthcare associated infections commonly diagnosed in burn patients, including catheter-related infections, pneumonia, and urinary tract infections.

Adverse outcomes including morbidity and mortality due to burn wound infection, sepsis, or another healthcare associated infection complication should be monitored in burn patients according to the extent of burn injury in order to assess the effectiveness of existing infection control practices within the centre's modern burn therapy program.

\section{Recommendations for Further Researches}

Identification of factors predisposing to lack of compliance with standard precautions in the ICUs.

Exploring the relationship between knowledge, previous exposure, and compliance to standard precaution guidelines.

\section{References}

1.Robson, MC. and Barbul, A. (2006): Guidelines for the best care of chronic wounds. Wound Rep Reg., 14: 647-8.

2.Sidler JA, Battegay M, Tschudin-Sutter S, Widmer AF, Weisser M. Enterococci, Clostridium difficile and ESBL-producing bacteria: epidemiology, clinical impact and prevention in ICU patients. Swiss Med Wkly. 2014 Sep 24;144.

3.Prevention of hospital-acquired infections, A practical guide,2nd edition. WHO, 2002.

4.BloemsmaGC, Dokter J, BoxmaH, OenIMMH. Mortality and causes of death in a burn centre. Burns. 2008 Dec; 34 (8): 1103-1107.

5.Palmieri, TL. and Greenhalgh, DG. (2002): Topical treatment of pediatric patients with burns: a practical guide. Am J ClinDermatol, 3: 529-534.

6.Nejad SB; Allegranzi B; Syed SB; Ellis B. and Pittet D. (2011): Health-care associated infection in Africa: a systematic review. Bulletin of the World Health Organization; 89:757765.

7.Afify M., Mahmoud N., Abd El Azzim G., El Desouky N. (2012): Fatal burn injuries: A five year retrospective autopsy study in Cairo city, Egypt. Egyptian Journal of Forensic Sciences, 2, 117-122.

8.Brusselaers N., Monstrey S., Vogelaers D., Hoste E, Blot S. (2010): Severe burn injury in europe: a systematic review of the incidence, etiology, morbidity, and mortality Critical Care, 14:R188

9.Panjeshahin MR, Lari AR, Talei A, et al.: Epidemiology and mortality of burns in the South West of Iran. Burns, 27: 219-26, 2001.

10.Hemeda M, Maher A, Mabrouk A. Epidemiology of burns admitted to Ain Shams University Burns Unit, Cairo, Egypt. Burns2003;29:353- 
358.

11.Vipul NA, Hemant VG. Study of burn deaths in Nagpur, Central India. Burns 2006;32:902-8.

12.Forjuoh SN. (2006): Burns in low- and middle-income countries: A review of available literature on descriptive epidemiology, risk factors, treatment, and prevention. Burns 32 (2006) $529-537$

13.Virendra K, Manoj KM, Sarita K. Fatal burns in Manipal area: a 10 year study. J Forensic Leg Med 2007;14:3-6.

14.Mabrouk A, Maher A, Nasser S. (2003): An epidemiology study of elderly burn patients in Ain Shams University Burn Unit, Cairo, Egypt. Burns. 29, 687-690.

15.Ozkurt Z., Altoparlak U. , IbaYilmaz S. , Erol S. , Ozden K., AkcAy M. (2012): Reducing hospital infection rates in the burn unit by adherence to infection control measures: A sixyear experience. Turk J Med Sci. 42 (1): $17-24$.

16.Al laham N.A., Elmanama A.A.,Tayh G.A. (2013): possible risk factors associated with burn wound Colonization in burn units of gaza strip hospitals, palestine. Annals of burns and fire disasters - vol. Xxvi n. 2 - june 2013.

17.Alwutaib AH., Abdulghafour YA., Alfadhli AK., Makboul G. and ElShazly MK. (2012): Knowledge and attitude of the physicians and nurses regarding blood borne infections in primary health care, Kuwait. Greener Journal of Medical Sciences, 2(4): 107-114.

18.El-Sayed MZ., Gomaa M. and AbdelAzizM. (2015): Nurses' Knowledge and Practice for Prevention of Infection in Burn Unit at a University Hospital: Suggested Nursing Guidelines. Journal of Nursing and Health Science, 4: 6269.

19.Ibrahim YS., Said AM. and Hamdy GK. (2011): Assessment of infection control practices in neonatal intensive care unit. The Egyptian Journal of Community medicine, 29(4):27-45.

20.Ashry MH. (2008): study of nosocomial burn wound infection in the burn unit of Alexandria main university hospital: incidence, patient characteristics and infection control procedures. Master thesis. Faculty of medicine, Alexandria University, department of community medicine and public health, 88-104.

21.Trick WE., Vernon MO., Welbel SF., Demarais P., Hayden MK. and Weinstein RA. (2007): Multicenter intervention program to increase adherence to hand hygiene recommendations and glove use and to reduce the incidence of antimicrobial resistance. Infect Control Hosp Epidemiol; 28: 42-9.

\section{How to cite this article:}

Hala Ahmed Magdy Mohamed El-Maghawry, Wafaa Atwa El Nem, Nahed Abd-Allah Sherif and Sohair Ahmed Hagag. 2016. An interventional study to decrease healthcare associated burn wound infections in the burn unit of Al Ahrar Hospital in Zagazig city, Sharkia Governorate. Int.J.Curr.Microbiol.App.Sci. 5(3): 566-578. doi: http://dx.doi.org/10.20546/ijcmas.2016.503.066 